\title{
Results of a hybrid procedure for patients with proximal left subclavian artery stenosis and coronary artery disease
}

\author{
Hao Hong, MD, ${ }^{a}$ Long Wu, MD, ${ }^{\mathrm{a}}$ Chao Yang, MD, ${ }^{\mathrm{b}}$ and Nian G. Dong, $\mathrm{MD}^{\mathrm{a}}$
}

\section{ABSTRACT}

Objective: To assess whether a hybrid approach to the treatment of coronary artery disease with proximal left subclavian artery stenosis is superior to a staged approach.

Methods: We retrospectively analyzed 20 patients who underwent percutaneous transluminal angioplasty (PTA) and stenting treatment combined with coronary artery bypass grafting on the same day (hybrid group) between January 2013 and October 2015, and compared them with 23 patients who underwent PTA and stenting followed by coronary artery bypass graft 4 weeks later (staged group) between January 2008 and December 2012. Demographic data, preoperative risk factors, intraoperative measures, and postoperative outcomes were analyzed.

Results: The demographic data and preoperative risk factors were similar in the 2 groups. The total hospital length of stay was similar in the 2 groups, with a median of 9 days (range, 6-12 days) in the hybrid group versus 9 days (range, 8-15 days) in the staged group $(P=.299)$. There were no postoperative complications (eg, myocardial infarction, stroke, renal failure) in either group. In both groups, the mortality rate was 0 in the hospital, at 1 month, and at 3 months. All patients in both groups had no symptom recurrence at follow-up. Angiography showed no significant difference in postoperative stenosis between the 2 groups at 3 months $(P=.762)$.

Conclusions: The hybrid procedure of PTA and stenting followed by coronary artery bypass grafting may be an effective approach for patients with concomitant proximal left subclavian artery stenosis and coronary artery disease. (J Thorac Cardiovasc Surg 2016;152:131-6)

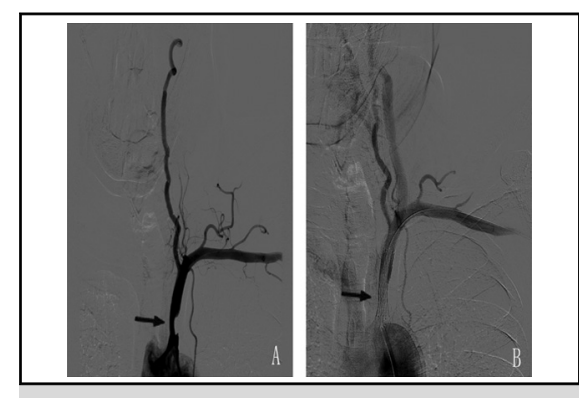

A, Angiogram showing left subclavian artery stenosis. $B$, No residual stenosis after stenting.

Central Message

A hybrid procedure of PTA and stenting followed by CABG may be an effective approach for patients with proximal LSA stenosis and CAD.

\section{Perspective}

Stenosis within the proximal LSA can lead to reversal of flow in patients with LIMA to LAD, resulting in myocardial ischemia after CABG. This lesion should be revascularized before CABG. The objective of this study was to assess whether a hybrid approach to the treatment of CAD with proximal LSA stenosis is superior to a staged approach.

See Editorial Commentary page 137
Use of the left internal mammary artery (LIMA) during coronary artery bypass grafting (CABG) surgery has become the gold standard for revascularization. Grafting the LIMA to the left anterior descending coronary artery (LAD) during CABG operations has the highest reported angiographic patency rate and is associated with the best survival and the fewest complications compared with other conduits. ${ }^{1-3}$

\footnotetext{
From the Departments of ${ }^{\mathrm{a} C a r d i o v a s c u l a r}$ Surgery and ${ }^{\mathrm{b}}$ Vascular Surgery, Union Hospital, Tongji Medical College, Huazhong University of Science and Technology, Wuhan, Hubei, China.

This work was supported by the National Natural Science Foundation of China (Grants 81300174 and 31330029).

Received for publication Nov 23, 2015; revisions received Feb 9, 2016; accepted for publication Feb 21, 2016; available ahead of print April 7, 2016.

Address for reprints: Nian G. Dong, MD, Department of Cardiovarscular Surgery, Union Hospital, Tongji Medical College, Huazhong University of Science and

Technology, 1277 Jiefang Rd, Wuhan 430022, China (E-mail: hhdongnianguo@ aliyun.com).

$0022-5223 / \$ 36.00$

Copyright (c) 2016 by The American Association for Thoracic Surgery

http://dx.doi.org/10.1016/j.jtcvs.2016.02.065
}

Any interruption in the hemodynamic integrity of this conduit, which includes proximal left subclavian artery stenosis (SAS), may jeopardize the clinical benefit and result in the coronary-subclavian steal syndrome (CSSS). ${ }^{4}$

Stenosis within the proximal left subclavian artery (LSA) is central in the pathophysiology of this syndrome. SAS can lead to reversal of flow in patients with a LIMA to LAD graft, resulting in myocardial ischemia. Any CABG candidate with a $\geq 10-\mathrm{mm} \mathrm{Hg}$ difference in systolic blood pressure between the 2 arms should have a presumptive diagnosis of SAS, and this lesion should be revascularized before CABG.

Scanning this QR code will take you to the article title page. 


$$
\begin{aligned}
& \text { Abbreviations and Acronyms } \\
& \text { CABG }=\text { coronary artery bypass graft } \\
& \text { CAD }=\text { coronary artery disease } \\
& \text { CSSS }=\text { coronary-subclavian steal syndrome } \\
& \text { ICU }=\text { intensive care unit } \\
& \text { LAD }=\text { left anterior descending coronary artery } \\
& \text { LIMA }=\text { left internal mammary artery } \\
& \text { LSA }=\text { left subclavian artery } \\
& \text { MI }=\text { myocardial infarction } \\
& \text { PTA }=\text { percutaneous transluminal angioplasty } \\
& \text { SAS }=\text { subclavian artery stenosis } \\
& \text { SD }=\text { standard deviation }
\end{aligned}
$$

Percutaneous intervention in the subclavian artery before CABG appears to be an attractive approach and is becoming the most popular in patients; however, there are little published data comparing hybrid and staged surgical approaches to concomitant SAS and coronary artery disease (CAD). Currently, there is no consensus as to which surgical approach is superior. We report the experience accumulated at a single institution for treatment of patients with CAD with SAS since 2008.

\section{METHODS}

After obtaining Institutional Review Board approval, we retrospectively reviewed the medical records of 20 patients who underwent PTA and stenting treatment combined with CABG on the same day between January 2013 and October 2015 (hybrid group). We compared their outcomes with those of a group of 23 patients who underwent PTA and stenting followed by CABG 4 weeks later between January 2008 and December 2012 (staged group). In all patients, the proximal LSA and coronary lesions were documented by angiography. Patients with stenosis corresponding to $\geq 50 \%$ (estimated reduction in vessel cross-sectional area) of the proximal LSA were treated. ${ }^{5,6}$ Preoperatively, all patients were reviewed by cardiac and vascular surgeons. Patients who had undergone emergency CABG surgery and those with left main coronary artery stenosis, right SAS, brachiocephalic artery stenosis, or stenosis located in the LSA distal to the LIMA were excluded from this analysis.

Demographic data, preoperative risk factors, intraoperative measures, and postoperative outcomes in the 2 groups were analyzed. Postoperative complications were defined as the presence of postoperative myocardial infarction (MI), cerebrovascular accident, renal failure, or death. Clinical follow-up was by though routine outpatient examination, with blood pressure measurements in both upper extremities and duplex ultrasound scanning of the treated subclavian artery. Patients underwent angiography at 3 months after the procedure. Symptom recurrence was defined as a return of angina, MI, and a bilateral blood pressure differential $>10 \mathrm{~mm} \mathrm{Hg}$. Significant recurrent stenosis corresponded to stenosis of $\geq 50 \%$, as defined by the Ad Hoc Subcommittee on Reporting Standards of the Society for Vascular Surgery and the North American Chapter of the International Society of Cardiovascular Surgery. ${ }^{5,6}$

\section{Operative Technique}

In the staged group, PTA and stenting were performed in the interventional operative suite with the patient under local anesthesia. In all patients, a transradial blood pressure monitoring line was placed in the opposite side to accurately compare blood pressure values between both upper extremities before and after treatment. A $6 \mathrm{~F}$ or $7 \mathrm{~F}$ sheath was used. Fluoroscopic guidance and road-mapping were used in all cases. Typically, the lesion was crossed with a 0.035 -inch angled hydrophilic guide wire (Glidewire; Boston Scientific, Watertown, Mass). The lesion was generally predilated with an angioplasty balloon (size, $5-8 \mathrm{~mm}$ ), followed by deployment of a balloon-expandable stent (Palmaz stent; Optapro, Cordis Endovascular, Miami, Fla). Stent size was chosen based on the size of the adjacent normal subclavian artery. Poststenting dilation was performed whenever residual stenosis occurred. After PTA and stenting of SAS, patients received a combination of aspirin $(100 \mathrm{mg} /$ day $)$ and clopidogrel ( $75 \mathrm{mg} /$ day) for 3 weeks. Therapy with dual antiplatelet agents was stopped 1 week before the CABG operation.

Off-pump CABG was routinely performed in the cardiac operating room. In brief, surgery was performed via a median sternotomy. The heart was displaced using a posterior pericardial stitch and large gauze swabs. The anastomotic site was secured with a suction-type tissue stabilizer (Octopus Tissue Stabilization System; Medtronic, Dublin, Ireland). The sequence of grafting in all patients was the LAD first, followed by the left circumflex coronary artery, diagonal artery, and right coronary artery. The LIMA was anastomosed to the LAD in all cases, and other grafts were performed using the saphenous vein. An intracoronary shunt was used during grafting on the LAD and distal right coronary artery. The patient was transferred to the intensive care unit (ICU) after surgery and received standardized postoperative care.

For the hybrid group, all procedures were performed on the same day in the hybrid operating room with the patient under general anesthesia. PTA and stenting were performed first, followed immediately by off-pump CABG. The patient was transferred to the ICU after surgery and received standardized postoperative care.

At discharge, all patients in the 2 groups were prescribed a combination of aspirin $200 \mathrm{mg} /$ day and clopidogrel $75 \mathrm{mg} /$ day for 1 year, followed by aspirin $200 \mathrm{mg} /$ day over the long term.

\section{Statistical Analysis}

All continuous variables are expressed as mean \pm standard deviation (SD). The independent $t$ test was used to compare continuous variables between groups with a normal distribution. Nonparametric variables are expressed as median and range (minimum to maximum). Nonparametric variables were compared using the Mann-Whitney $U$ test, and dichotomous variables were compared by $\chi^{2}$ analysis. All statistical analyses were done using SPSS version 17 (SPSS Inc, Chicago Ill).

\section{RESULTS}

Demographic data, preoperative risk factors, intraoperative measures, and postoperative outcomes in the 2 groups are summarized in Tables 1-4. Demographic data and preoperative risk factors were similar in the hybrid and staged groups (Table 1).

\section{PTA and Stenting}

In both groups, all SAS lesions were atherosclerotic in etiology and located in the LSA proximal to the LIMA (Figure 1,A). All patients were treated using femoral access. The pre-PTA stenosis and gradient were similar in the 2 groups (Table 2). The technical success rate was $100 \%$ in both groups (Figure 1, B). Post-PTA stenosis and gradient also were similar in the 2 groups (Table 2). All patients in both groups exhibited equalization of arm blood pressures after the procedure, and thus were considered initially clinical successful. 
TABLE 1. Patient demographic data and preoperative risk factors

\begin{tabular}{lccr}
\hline \multicolumn{1}{c}{ Variable } & $\begin{array}{c}\text { Hybrid group } \\
(\mathbf{n}=\mathbf{2 0})\end{array}$ & $\begin{array}{c}\text { Staged group } \\
(\mathbf{n}=\mathbf{2 3})\end{array}$ & $\boldsymbol{P}$ value \\
\hline Age, y, mean \pm SD & $61 \pm 3$ & $63 \pm 3$ & .101 \\
Male sex, n (\%) & $9(45)$ & $10(43.5)$ & .920 \\
BMI, mean \pm SD & $22 \pm 2$ & $22.4 \pm 2.5$ & .574 \\
EF, \%, mean \pm SD & $54.9 \pm 5.4$ & $52 \pm 6.5$ & .121 \\
Diabetes mellitus, n (\%) & $7(35)$ & $7(30.4)$ & .750 \\
Hypertension, n (\%) & $14(70)$ & $17(74)$ & .775 \\
COPD, n (\%) & $5(25)$ & $6(26)$ & .935 \\
CVA, n (\%) & 0 & $1(4.3)$ & 1.000 \\
Dyslipidemia, n (\%) & $12(60)$ & $13(56.5)$ & .818 \\
Current smoker, n $(\%)$ & $2(10)$ & $3(13)$ & 1.000 \\
Previous MI, n $(\%)$ & 0 & 0 & \\
Previous surgery, n $(\%)$ & 0 & 0 & \\
\hline
\end{tabular}

$S D$, Standard deviation; $B M I$, body mass index; $E F$, ejection fraction; $C O P D$, chronic obstructive pulmonary disease; $C V A$, cerebrovascular accident; $M I$, myocardial infarction.

\section{CABG}

There was no significant difference between the 2 groups in the number of diseased vessels. In the hybrid group, 9 patients (45\%) underwent 3-vessel CABG and $11(55 \%)$ underwent 4-vessel $\mathrm{CABG}$; in the staged group, these numbers were $10(43.5 \%)$ and $13(56.5 \%)$, respectively $(P=.92$ for both comparisons) (Table 2).

\section{Clinical Outcomes}

In the staged group, no adverse events occurred in the interval between the PTA and the CABG procedure. Both groups had a mortality rate of 0 in the hospital, at 1 month, and at 3 months. No patient in either group experienced a postoperative complication (ie, MI, cerebrovascular accident, or renal failure). The mean number of units of packed red blood cells transfused was $3.8 \pm 0.8 \mathrm{U}$ in the hybrid group and $4.0 \pm 0.8 \mathrm{U}$ in the staged group $(P=.345)$. No patient in either group required reoperation for postoperative bleeding. Prolonged intubation was required for 2

TABLE 2. Operative characteristics

\begin{tabular}{lccc}
\hline Characteristic & $\begin{array}{c}\text { Hybrid group } \\
(\mathbf{n}=\mathbf{2 0})\end{array}$ & $\begin{array}{c}\text { Staged group } \\
(\mathbf{n}=\mathbf{2 3})\end{array}$ & $\boldsymbol{P}$ value \\
\hline Diseased vessels, n (\%) & & & \\
$\quad$ Three & $9(45)$ & $10(43.5)$ & .920 \\
Four & $11(55)$ & $13(56.5)$ & .920 \\
Pre-PTA stenosis, \% & & & .178 \\
$\quad$ Minimum & 55 & 55 & \\
Median & 85 & 80 & \\
Maximum & 95 & 95 & \\
Post-PTA stenosis, \% & 0 & 0 & \\
Pre-PTA gradient, \% & & & \\
Minimum & 20 & 30 & \\
Median & 30 & 40 & \\
Maximum & 50 & 55 & \\
Post-PTA gradient, \% & 0 & 0 & \\
\hline PTA Prcurg
\end{tabular}

PTA, Percutaneous transluminal angioplasty.
TABLE 3. Postoperative outcomes in hospital

\begin{tabular}{|c|c|c|c|}
\hline Outcome & $\begin{array}{l}\text { Hybrid group } \\
\quad(\mathbf{n}=\mathbf{2 0})\end{array}$ & $\begin{array}{l}\text { Staged group } \\
\quad(\mathbf{n}=\mathbf{2 3})\end{array}$ & $P$ value \\
\hline Prolonged ventilation, $\mathrm{n}(\%)$ & $2(10)$ & $3(13)$ & 1.000 \\
\hline ICU length of stay, $h$ & & & .267 \\
\hline Minimum & 31 & 30 & \\
\hline Median & 36 & 40 & \\
\hline Maximum & 81 & 89 & \\
\hline Hospital length of stay, $d$ & & & .299 \\
\hline Minimum & 6 & 8 & \\
\hline Median & 9 & 9 & \\
\hline Maximum & 12 & 15 & \\
\hline $\begin{array}{l}\text { PRBC units transfused, } \\
\text { mean } \pm \mathrm{SD}\end{array}$ & $3.8 \pm 0.8$ & $4.0 \pm 0.8$ & .345 \\
\hline $\begin{array}{l}\text { Bleeding requiring } \\
\text { reoperation, } \mathrm{n}(\%)\end{array}$ & 0 & 0 & \\
\hline $\begin{array}{l}\text { Bilateral arm blood pressure } \\
\text { differential }>10 \mathrm{~mm} \mathrm{Hg} \\
\mathrm{n}(\%)\end{array}$ & 0 & 0 & \\
\hline Angina, n (\%) & 0 & 0 & \\
\hline Postoperative MI, n (\%) & 0 & 0 & \\
\hline $\begin{array}{l}\text { Postoperative renal failure, } \\
\mathrm{n}(\%)\end{array}$ & 0 & 0 & \\
\hline Postoperative CVA, n (\%) & 0 & 0 & \\
\hline Mortality, n (\%) & 0 & 0 & \\
\hline
\end{tabular}

patients $(10 \%)$ in the hybrid group and 3 patients $(13 \%)$ in the staged group $(P=1.000)$. The median ICU length of stay was 36 hours (range, 31-81 hours) for the hybrid

TABLE 4. Postoperative outcomes at 1 month and 3 months

\begin{tabular}{|c|c|c|c|}
\hline Outcome & $\begin{array}{l}\text { Hybrid group } \\
\quad(n=20)\end{array}$ & $\begin{array}{l}\text { Staged group } \\
\quad(\mathbf{n}=\mathbf{2 3})\end{array}$ & $P$ value \\
\hline \multicolumn{4}{|c|}{ Bilateral arm blood pressure differential $>10 \%, \mathrm{n}$} \\
\hline $1 \mathrm{mo}$ & 0 & 0 & \\
\hline $3 \mathrm{mo}$ & 0 & 0 & \\
\hline \multicolumn{4}{|l|}{ Angina, $\mathrm{n}$} \\
\hline $1 \mathrm{mo}$ & 0 & 0 & \\
\hline $3 \mathrm{mo}$ & 0 & 0 & \\
\hline \multicolumn{4}{|l|}{ Postoperative MI, n } \\
\hline $1 \mathrm{mo}$ & 0 & 0 & \\
\hline $3 \mathrm{mo}$ & 0 & 0 & \\
\hline \multicolumn{4}{|c|}{ Postoperative renal failure, $\mathrm{n}$} \\
\hline $1 \mathrm{mo}$ & 0 & 0 & \\
\hline $3 \mathrm{mo}$ & 0 & 0 & \\
\hline \multicolumn{4}{|l|}{ Postoperative CVA, $\mathrm{n}$} \\
\hline $1 \mathrm{mo}$ & 0 & 0 & \\
\hline $3 \mathrm{mo}$ & 0 & 0 & \\
\hline \multicolumn{4}{|l|}{ Mortality, $\mathrm{n}$} \\
\hline $1 \mathrm{mo}$ & 0 & 0 & \\
\hline $3 \mathrm{mo}$ & 0 & 0 & \\
\hline Stenosis (3 mo), \% & & & .762 \\
\hline Minimum & 0 & 0 & \\
\hline Median & 5 & 5 & \\
\hline Maximum & 15 & 15 & \\
\hline
\end{tabular}



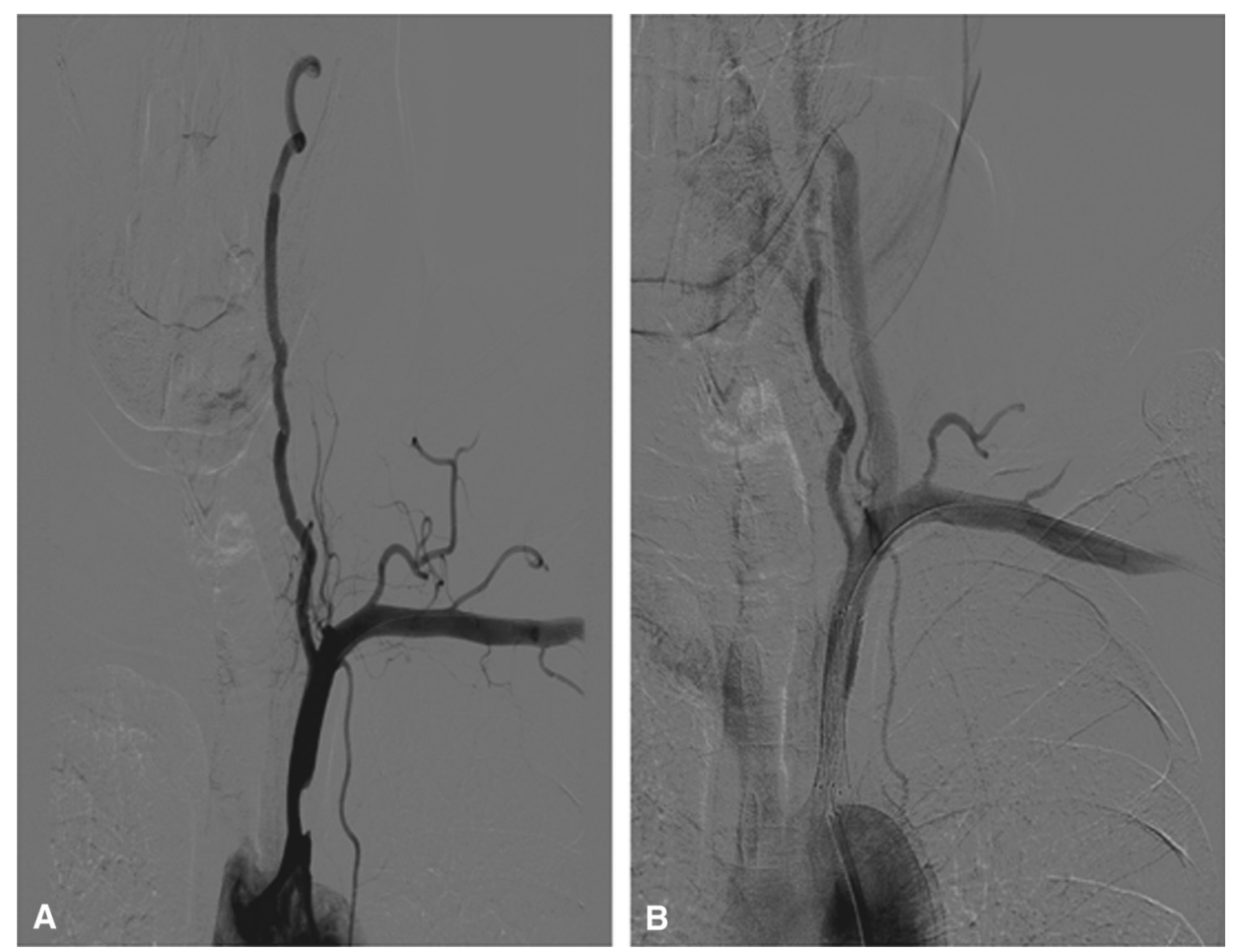

FIGURE 1. A, Angiogram showing SAS in the LSA proximal to the origin of the LIMA. B, Arteriogram obtained after balloon angioplasty and stenting showing no residual stenosis.

group and 40 hours (range, 30-89 hours) for the staged group $(P=.267)$. The total hospital length stay was similar in the 2 groups (median, 9 days [range, 6-12 days] vs 9 days [range, 8 -15 days]; $P=.299$ ) (Table 3).

Complete information at 1 month and 3 months postprocedure was obtained for all patients in both groups. Symptoms were evaluated in the hospital. No patient in either group had symptom recurrence at follow-up. Angiography showed no significant difference in postoperative stenosis between the 2 groups at 3 months $(P=.762)$ (Table 4$)$.

\section{DISCUSSION}

CSSS has been known for several decades, with early case reports appearing in the literature in the 1970s. ${ }^{4,7}$ The dangerous nature of CSSS has been acknowledged, and the importance of its detection before the use of the LIMA in CABG procedures has been emphasized. Overall, more than $70 \%$ of patients with significant $C A D$ have some thoracic aorta or brachiocephalic artery disease. ${ }^{8}$ Among all of the brachiocephalic artery origins, the LSA is usually the most severely affected. ${ }^{9}$ Based on clinical and angiographic studies, the incidence of SAS in patients undergoing CABG ranges from $0.5 \%$ to $1.1 \% .^{10-12}$

For our hybrid group, we retrospectively evaluated the records of 2636 consecutive patients referred for CABG at our institution between January 2013 and October 2015, and identified 1132 patients $(42.9 \%)$ who underwent LSA angiography immediately after diagnostic coronary angiography. Significant left SAS was found in 20 of those 1132 patients $(1.8 \%)$. For our staged group, we retrospectively evaluated the records of 4512 consecutive patients referred for CABG between January 2008 and December 2012, and identified 1533 patients (34\%) who underwent LSA angiography immediately after diagnostic coronary angiography. Significant left SAS was found in 23 of those 1533 patients $(1.5 \%)$.

The ability to diagnose LSA stenosis before CABG is planned relies heavily on clinical suspicion. Symptoms suggesting the presence of LSA stenosis include claudication, coolness, numbness, pain at rest, and discoloration of the left upper extremity. Symptoms of vertebrobasilar stenosis also may manifest. A discrepancy of $>10 \mathrm{~mm} \mathrm{Hg}$ between bilateral arm cuff pressure measurement is the best available indicator raising suspicion for SAS. ${ }^{13}$ In our experience, screening for LSA stenosis should be routinely performed in all patients awaiting CABG. Any patient being evaluated for CABG with signs and symptoms of LSA stenosis should undergo further evaluation with angiography.

Patients who develop a hemodynamically significant LSA stenosis should undergo treatment of the LSA lesion. Treatment options include PTA and stenting or surgical revascularization. Overall, surgical repair has resulted in durable long-term patency of $>90 \%$, with low morbidity 
and mortality. ${ }^{14}$ Surgical subclavian artery reconstruction (with either PTFE aortoaxillary bypass or carotidsubclavian transposition) or an LSA endarterectomy are surgical options that can be performed at the time of the CABG. ${ }^{15}$ The morbidity and mortality rates associated with these surgical options are raised markedly by the presence of severe CAD, however. ${ }^{16}$ For this reason, there has been great interest in the application of endovascular techniques. A study comparing stenting of brachiocephalic vessels with the published surgical experience demonstrated equal effectiveness but fewer complications, and suggested that stenting should be considered as first-line therapy for subclavian or brachiocephalic obstruction. ${ }^{17}$ If the patient with technical failure had a total occlusion, and the guide wire could not be passed despite femoral and brachial approaches, then the patient should be referred to surgical options.

Although PTA and stenting is an attractive approach to treat LSA stenosis, there are little published data regarding the timing of $\mathrm{CABG}$ after stenting. In the present study, the operative results were similar in the hybrid and staged groups. In addition, there were no significant between-group differences in postoperative and short-term follow-up outcomes.

This feasibility of an elective hybrid procedure of PTA and stenting combined with off-pump CABG produced satisfactory outcomes in this early experience and suggests an alternative treatment for patients with CAD and LSA stenosis. We see several benefits of this procedure. First, the combined approach may be more convenient for the patient and more cost-effective than the staged approach. This approach requires a high degree of coordination between the cardiac surgeon and the vascular surgeon, which may be facilitated by the creation of a hybrid operating room designed for performing both procedures. Fortunately, our hospital has owned a hybrid operating room since January 2013. Before 2013, patients could be treated only by staged surgery. After 2013, patients could be treated by combined surgery in the hybrid operating room.

Second, the combined approach may be more suitable for patients requiring emergent $\mathrm{CABG}$. In our study, during the 1-month interval between the 2 surgeries, patients in the staged group were at risk for preoperative adverse events, such as MI, in the presence of CAD, although no such events occurred. In emergent CABG, use of the free LIMA introduces another option and raises concerns about patency compared with use of the in situ LIMA. In summary, the majority of available modern data supports the use of the free LIMA as a conduit that can provide excellent long-term patency comparable to that achieved with in situ LIMA. ${ }^{13}$ But patency rates of the free LIMA depend more significantly on degree of native coronary stenosis, with improved patency with native vessel proximal stenosis
$>60 \%{ }^{13}$ Furthermore, technical considerations of the proximal anastomosis are critical and must be left up to the individual surgeon's expertise and judgment. ${ }^{13}$

Angiography revealed severe stenosis of the proximal LSA and demonstrated little anterograde flow in LIMA, and reversal of flow within the vertebral artery in some patients. After PTA and stenting, angiography revealed immediate improvement of LIMA graft flow. Thus, for patients requiring emergent revascularization, placement of an in situ LIMA to the LAD would appear to be a safe and durable technique, with patency rates comparable to those of free LIMA grafts to the LAD.

The present study has several limitations. First, it is a single-center, retrospective study of a heterogeneous group of patients. Patient follow-up was limited to 3 months, and thus no statement may be made regarding long-term differences in outcomes. A rather subjective endpoint was used. These are uncontrollable confounders, and in view of this, the results can only be interpreted as hypothesisgenerating. Moreover, there are many other unanswered questions, including the optimal timing between procedures, optimal management of antiplatelet therapy, and long-term restenosis rate. These are questions for which only a well-designed and adequately powered randomized, controlled trial can provide answers.

\section{CONCLUSIONS}

Our experience has shown that a hybrid procedure of PTA and stenting followed by $\mathrm{CABG}$ may be an effective approach for treating patients with concomitant proximal LSA stenosis and CAD. Compared with a staged approach to these surgeries, this hybrid approach can be undertaken with similar operative results and postoperative and shortterm follow-up outcomes. More research is needed to compare the long-term differences in outcomes, however, and a multicenter prospective randomized trial should be pursued to address this question.

\section{Conflict of Interest Statement}

Authors have nothing to disclose with regard to commercial support.

\section{References}

1. Loop FD, Lytle BW, Cosgrove DM, Stewart RW, Goormastic M, Williams GW, et al. Influence of the internal-mammary-artery graft on 10-year survival and other cardiac events. N Engl J Med. 1986;314:1-6.

2. Lytle BW, Loop FD, Cosgrove DM, Ratliff NB, Easley K, Taylor PC. Long-term (5 to 12 years) serial studies of internal mammary artery and saphenous vein coronary bypass grafts. J Thorac Cardiovasc Surg. 1985;89:248-58.

3. Cameron A, Kemp HG Jr, Green GE. Bypass surgery with the internal mammary artery graft: 15-year follow-up. Circulation. 1986;74(5 Pt 2):III30-6.

4. Harjola PT, Valle M. The importance of aortic arch or subclavian angiography before coronary reconstruction. Chest. 1974;66:436-8.

5. Rutherford RB. Standards for evaluating results of interventional therapy for peripheral vascular disease. Circulation. 1991;83(2 Suppl):I6-11.

6. Rutherford RB, Flanigan DP, Gupta SK, Johnston KW, Karmody A, Whittemore AD, et al. Suggested standards for reports dealing with lower 
extremity ischemia. Prepared by the Ad Hoc Committee on Reporting Standards, Society for Vascular Surgery/North American Chapter, International Society for Cardiovascular Surgery. J Vasc Surg. 1986;4:80-94.

7. Tyras DH, Barner HB. Coronary-subclavian steal. Arch Surg. 1977;112:1125-7.

8. Khoury Z, Schwartz R, Gottlieb S, Chenzbraun A, Stern S, Keren A. Relation of coronary artery disease to atherosclerotic disease in the aorta, carotid, and femoral arteries evaluated by ultrasound. Am J Cardiol. 1997;80:1429-33.

9. Sisto T. Atherosclerosis in internal mammary and related arteries. Scand J Thorac Cardiovasc Surg. 1990;24:7-11.

10. Green GE. Rate of blood flow from the internal mammary artery. Surgery. 1971; 70:809-13.

11. Barner HB. Double internal mammary-coronary artery bypass. Arch Surg. 1974; 109:627-30.

12. Geha AS, Krone RJ, McCormick JR, Baue AE. Selection of coronary bypass. Anatomic, physiological, and angiographic considerations of vein and mammary artery grafts. J Thorac Cardiovasc Surg. 1975;70:414-31.

13. Rogers JH, Calhoun RF II. Diagnosis and management of subclavian artery stenosis prior to coronary artery bypass grafting in the current era. J Card Surg. 2007;22:20-5.
14. Law MM, Colburn MD, Moore WS, Quiñones-Baldrich WJ, Machleder HI, Gelabert HA. Carotid-subclavian bypass for brachiocephalic occlusive disease: choice of conduit and long-term follow-up. Stroke. 1995;26:1565-71.

15. Ochi M, Yamauchi S, Yajima T, Bessho R, Tanaka S. Simultaneous subclavian artery reconstruction in coronary artery bypass grafting. Ann Thorac Surg. 1997:63:1284-7.

16. Angle JF, Matsumoto AH, McGraw JK, Spinosa DJ, Hagspiel KD, Leung DA, et al. Percutaneous angioplasty and stenting of left subclavian artery stenosis in patients with left internal mammary-coronary bypass grafts: clinical experience and long-term follow-up. Vasc Endovascular Surg. 2003; 37:89-97.

17. Hadjipetrou P, Cox S, Piemonte T, Eisenhauer A. Percutaneous revascularization of atherosclerotic obstruction of aortic arch vessels. J Am Coll Cardiol. 1999;33: $1238-45$.

Key Words: left subclavian artery stenosis, coronarysubclavian steal syndrome, coronary artery bypass grafting, percutaneous intervention

Readers who found these articles interesting may also like to read the following papers found in recent and future issues of our sister publications, Seminars in Thoracic and Cardiovascular Surgery and Operative Techniques in Thoracic and Cardiovascular Surgery!

\section{Acquired: Coronary Artery Disease}

Original Submissions: Micromorphology of Skeletonized and Pedicled Internal Thoracic and Radial Arteries. Sergey Mamchur. Semin Thorac Cardiovasc Surg 2015; Summer; 27(2):115-120.

Editorial Commentary: Harvesting Arterial Grafts: Barebones or More. Faisal G. Bakaeen. Semin Thorac Cardiovasc Surg 2015; 27(2):121-122. 